\title{
STUDIES OF THE REFLEX ACTIVITY OF THE EXTERNAL SPHINCTER ANI IN SPINAL MAN
}

\author{
By \\ J. MeLZAK, M.D. \\ National Spinal Injuries Centre, Stoke Mandeville Hospital, Aylesbury \\ and \\ N. H. PorTeR, F.R.C.S. \\ Department of Surgery, Guy's Hospital, London
}

\section{INTRODUCTION}

IN normal man, the anus remains closed unless faeces or wind are to be evacuated. Anal closure is maintained by the tone of the anal sphincters. The importance of the internal and external anal sphincters in maintaining anal closure has for long been a controversial subject. Gowers (1877) made classical contributions to the understanding of visceral reflexes and sphincter activity. He postulated a complex lumbar reflex centre controlling the function of the rectum and anal sphincter. $\mathrm{He}$ demonstrated tonic contraction of the anal sphincter in paraplegic patients, provided the lumbar segments of the cord and the corresponding motor and sensory nerves were intact. Starling (1900) considered that both sphincters were tonically contracted. Frankl-Hochwart and Fröhlich (1900) found that 60 per cent. of the tonic closure of the anus in dogs was due to the activity of the external sphincter. Matti (1909, 1910) considered that both sphincters were tonically contracted in man and dogs. Denny-Brown and Robertson (1935) concluded from their studies that the postural tone of the internal anal sphincter was a local phenomenon and related to the peripheral nervous plexus. They also held the view that the external sphincter on the other hand was not tonically contracted.

The external anal sphincter has repeatedly been the subject of electromyographic investigation. In I930, Beck, using steel needle electrodes and a string galvanometer, observed action potentials on contraction and relaxation of this muscle in a number of dogs and in one man. Floyd and Walls (1953), using surface electrodes, showed conclusively by means of electromyography that the human external sphincter ani is always in a state of tonic contraction during waking and sleeping hours. Bishop et al. (1956) found that a similar condition prevailed in the cat and that it was due to a spinal reflex. Bors and Blinn (1958), Taverner and Smiddy (1959) and Porter (196I), using needle electrodes inserted into the external anal sphincter and pubo-rectalis in man, also found constant muscle contraction at rest.

The effect of rectal filling on the anal sphincters has also given rise to controversy and claimed the attention of some notable investigators, among them Masius (1868), Gowers (I877), Head and Riddoch (1917), Denny-Brown and Robertson (1935), Gaston (1948), Goligher and Hughes (195I). These investigators based their observations on records obtained from intra-anal balloons and clinical observations. Their findings are contradictory, due to confusion in interpreting the respective actions of the superimposed internal and external sphincters. Bishop, Garry, Roberts and Todd (1956) investigated this problem in the cat, using needle electrodes, and found that rectal distension eventually inhibits tonic con- 
traction of the external sphincter ani after an initial excitatory phase. Porter (I96I, I962) and Parks, Porter and Melzak (1963) made similar observations in the normal human subject.

The purpose of the present paper is to give an account of studies on the reflex activity of the external anal sphincter in spinal man and on the factors influencing this activity.

\section{CLINICAL MATERIAL}

Electromyography of the external anal sphincter was studied in 42 patients with spinal cord lesions. There were 34 cord lesions, 3 conus lesions, 4 cauda equina lesions and I case of tabes dorsalis. All cases except the tabes dorsalis were complete lesions. Only cases with firmly established neurological level were chosen. Three cases were examined while in the stage of spinal shock.

In 4 cases, laminectomy was performed before the patients were admitted to the National Spinal Injuries Centre, and in 9 cases transection or severe anatomical damage of the spinal cord was verified at laminectomy. In 3 cases ( $\mathrm{N}_{32}, \mathrm{~J}$. B.; $\mathrm{N}_{34}$, M. C.; N38, E. S.) with complete lesions at $\mathrm{T} 6, \mathrm{~T}_{7}$, and $\mathrm{T}_{\mathrm{I}}$, intrathecal alcohol block was performed by Dr. Guttmann because of intractable spasticity, thus transforming the spastic paraplegia into a flaccid one. As far as the level of the cord injury is concerned, there were 3 cervical lesions, 9 upper dorsal, 20 lower dorsal, 5 lumbar and 4 cases with cauda equina lesions. There were 29 spastic cases and I 2 flaccid cases (apart from I case of tabes dorsalis).

Table I shows details of the level and type of lesion.

TABLE I

Level and Type of Lesion

\begin{tabular}{|c|c|c|c|} 
& Spastic & Flaccid & Total \\
\hline Cervical & 3 & - & 3 \\
\hline Dorsal TI-T6 & 8 & I & 9 \\
Dorsal T7-TI2 & I5 & 5 & 20 \\
Lumbar & 4 & I & 5 \\
Cauda equina & - & 4 & 4 \\
\hline Tabes & - & I & I \\
\hline Total & 30 & I2 & 42 \\
\hline
\end{tabular}

\section{METHOD}

Electromyography was employed to record contraction and relaxation in the striated muscle of the external anal sphincter. Action potentials were picked up by a concentric needle electrode, as this type of electrode has the advantage that it records impulses over a small field in the immediate vicinity of the needle tip (Adrian \& Bronk, I928). The action potentials were amplified and shown on an oscilloscope screen, at the same time they were photographed to provide a permanent record for subsequent analysis.

Intra-anal balloon recordings for studying activity of the external sphincter were avoided in many experiments since stimulation of the anal sphincters is inevitable when a balloon is placed in the anal canal and the pressures recorded are 
in any case the sum of the activity of both the internal and external sphincters. Observations based solely on balloon measurements of sphincter activity are thus open to considerable criticism. Balloons however, were used in certain stages of this study as a stimulus to distend the rectum or to stretch the anal sphincters (figs. I $a$ and $b$ ). In either case a standard Miller-Abbot balloon was used. For

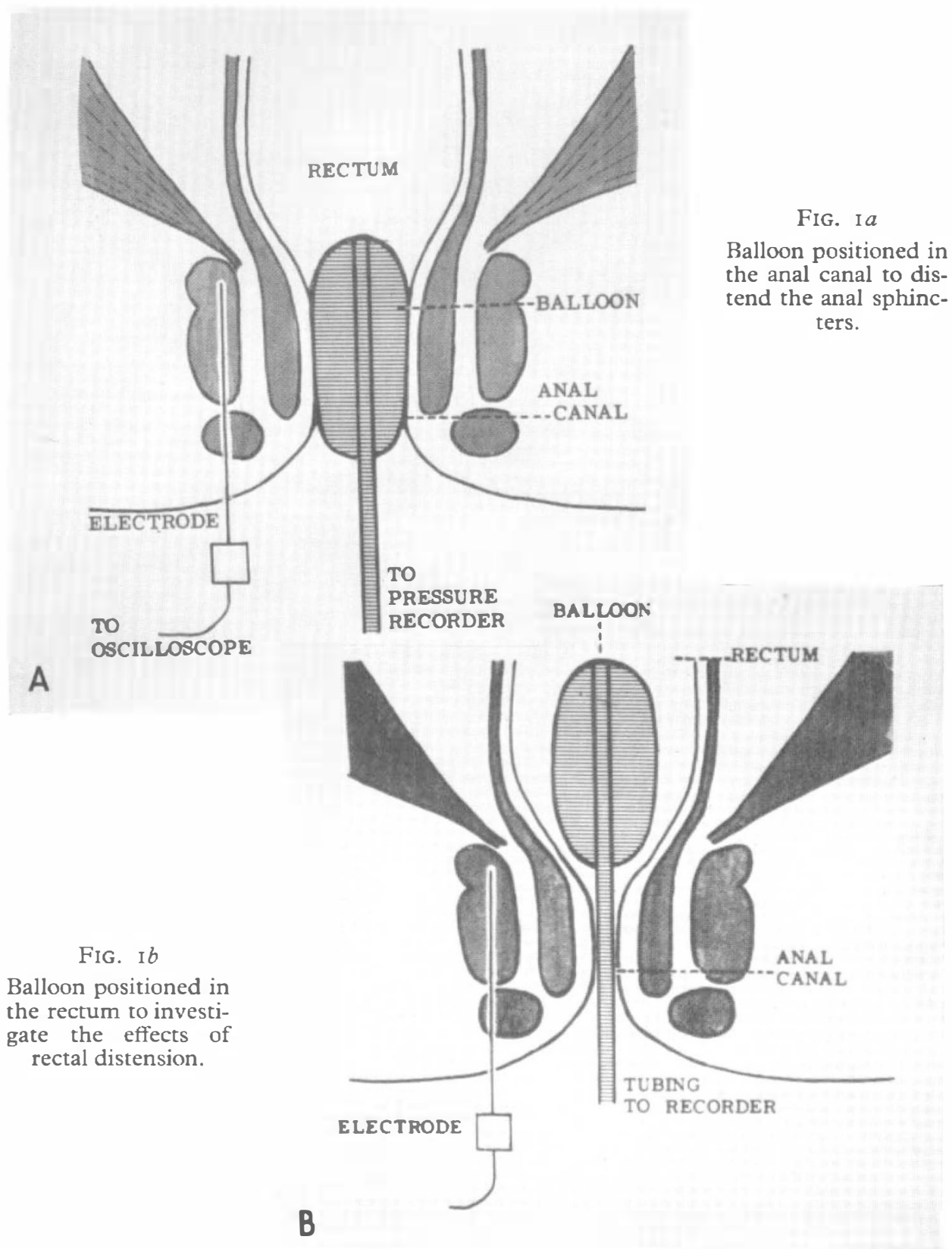


rectal distension it was placed five to eight centimeters above the anal verge and inflated with successive additions of $50 \mathrm{ml}$. of air. The responses of the rectal wall to distension were measured by continuously recording the pressure changes in the balloon. Simultaneously the responses of the external anal sphincter were recorded electromyographically.

\section{EXPERIMENTAL PROCEDURE}

During examination the patient was placed in the lateral position, and the needle electrode was inserted through the perianal skin into the deepest part of the external sphincter or pubo-rectalis, as estimated by concurrent digital examination of the anal canal. A certain amount of 'searching' with the needle tip may be required to find maximum activity. The examining finger is then withdrawn from the anal canal. An interval of Io minutes was allowed for any induced activity to settle down, then a tracing was made of the rest basal activity. Certain direct stimuli are then applied and the resulting change in the reflex activity of the external sphincter ani recorded.

\section{RESULTS}

An electromyographic record of the external sphincter of a normal subject at rest shows continous electrical activity (fig. 2). The muscles of the pelvic floor are unique, in that they are the only skeletal muscles which maintain a continuous discharge of impulses from the anterior horn cells which excite them.

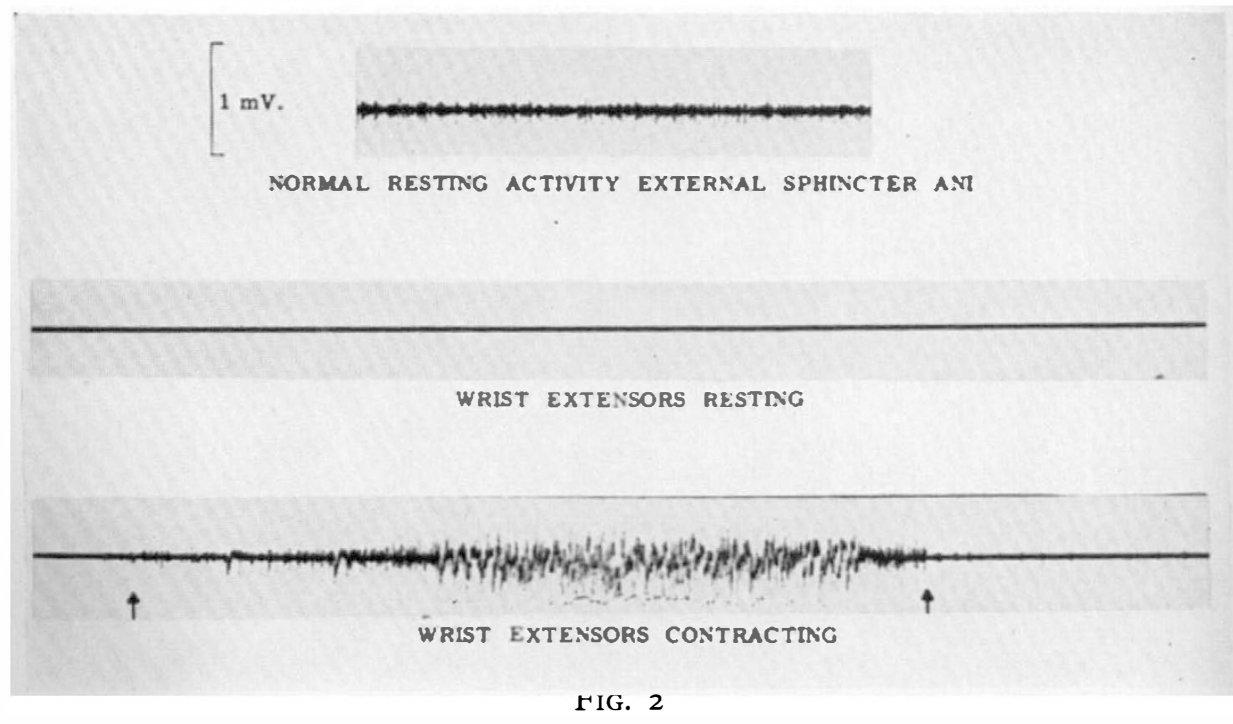

The external sphincter ani shows continuous activity with the patient resting; in contrast the wrist extensors are inactive unless a volitional contraction is made.

A study of spastic paraplegic patients shows that in all cases continuous contraction is still maintained in the external sphincter after transection of the spinal cord above the level of the third lumbar segment (fig. 3). 


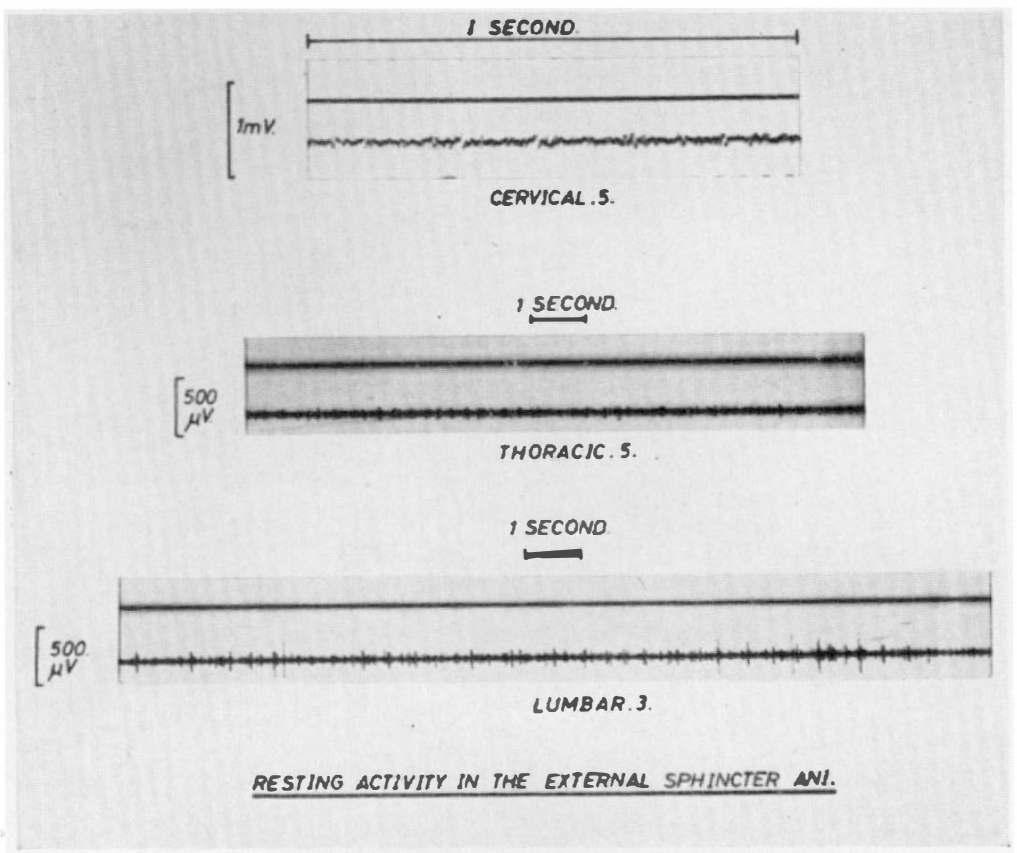

FIG. 3

Three cases of complete spastic paraplegia at different levels show continuous activity of the external sphincter.

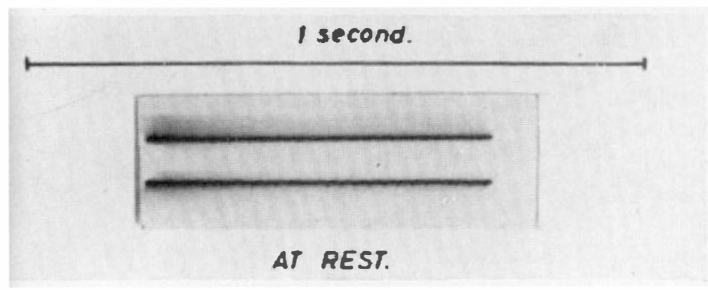

FIG. 4 External rectal sphincter in tabes dorsalis at rest and on voluntary contraction.

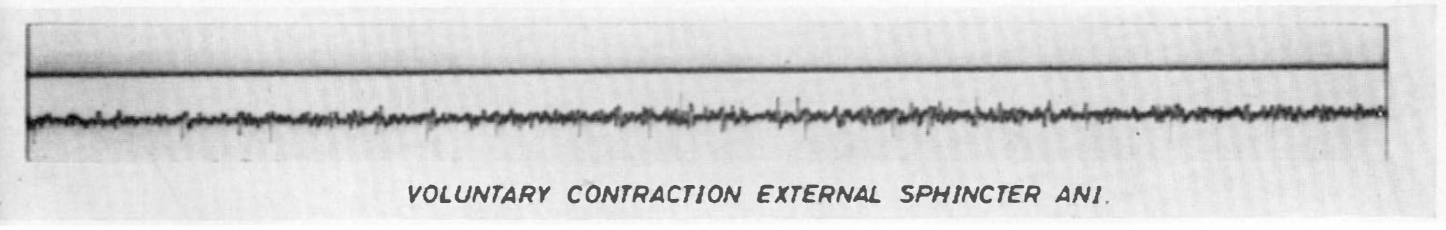

In striking contrast the external sphincter ani was found completely inactive during spinal shock, before reflex activity in the isolated cord following complete cord transection had recovered (figs. $5 a$ and $b$ ). It was also inactive when conduction via sacral roots was abolished as a result of an intra-thecal alcohol injection (Guttmann, 1947, 1953) or following traumatic cauda equina lesion. 


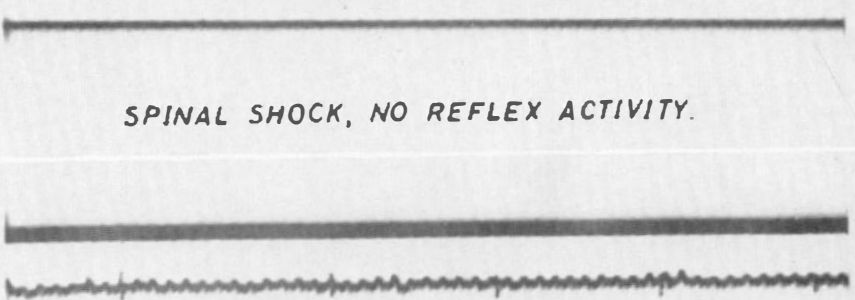

PARTIAL RECOVERY

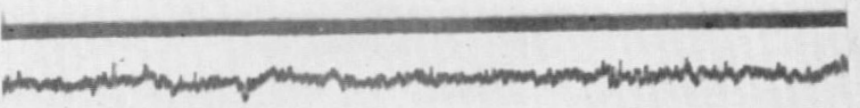

FULL RECOVERY OF REFLEX CONTRACTION.

PARAPLEGIA C 6 .

FIG. $5 a$

Recovery of reflex activity of the external rectal sphincter from spinal shock.

\section{SECOND.}

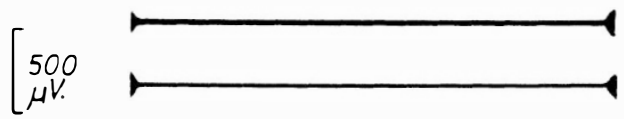

CAUDA EQUINA LESION S.2.

1 SECOND.

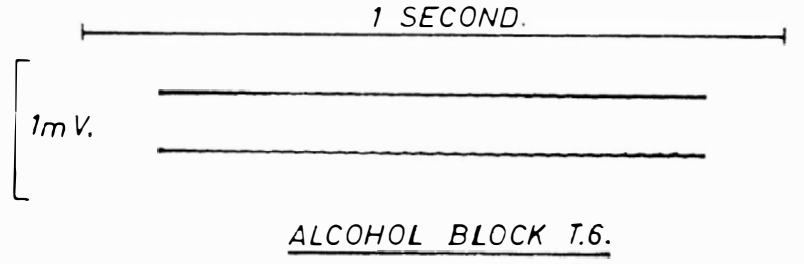

FIG. $5 b$

No evidence of reflex activity of the external sphincter ani in a patient with a lesion of the cauda equina below $\mathrm{S}_{2}$ and in another after intrathecal alcohol injection. 
Study of patients with tabes dorsalis also showed absence of resting activity in the external sphincter ani (Porter, 1962). In these cases however, the presence of motor unit activity in response to voluntary contraction demonstrated the integrity of the motor pathway (fig. 4). The absence of continuous activity in the external sphincter at rest in this disease which is known to destroy proprioceptive pathways proved the importance of these pathways for maintaining the postural tone of the external sphincter.

\section{FACTORS AFFECTING RESTING CONTRACTION IN THE EXTERNAL SPHINCTER ANI}

There are numerous stimuli which modify the resting contraction of the external sphincter, these may be excitatory or inhibitory and sometimes they may have a dual effect.

Raised Intra-Abdominal Pressure. A rise of intra-abdominal pressure occurs under a variety of circumstances, it may be transient or prolonged. In paraplegic patients the response to changes in intra-abdominal pressures varies in proportion to the degree of voluntary control that is retained over the abdominal muscles. This is demonstrated in the following experiments:

Coughing results in raising intra-abdominal pressure for a short period. The external sphincter responds by a simultaneous increase in activity. The lower the level of cord section the greater is the response in the sphincter (fig. 6). This is to be expected, as in lower lesions more of the trunk muscles retain their innervation and intra-abdominal pressure is more effectively increased. Movements of the trunk likewise increase intraabdominal pressure and cause an increase in external sphincter contraction (fig. 7). Bearing down as in defaecation raises intra-abdominal pressure for as long as the straining effort is maintained. The capacity to do this increases in proportion to the sparing of function of the abdominal muscles. With full voluntary control of the abdominal muscles the effect of bearing down is at first excitatory and then inhibitory to the pelvic floor. This dual effect is illustrated by studies on a patient with complete spinal transection at the first lumbar level (fig. 8). Bearing down at first excites increased contraction which is, however, rapidly followed by complete relaxation of the external sphincter. The anus remains closed throughout. As soon as

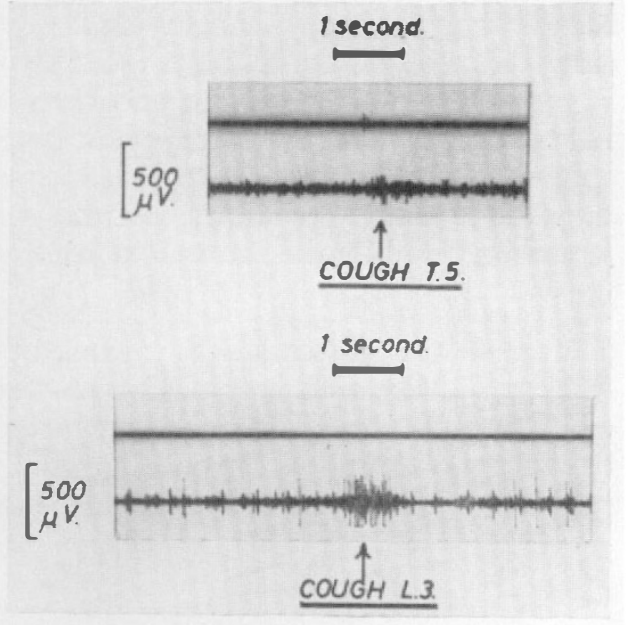

FIG. 6 Coughing excites an increase in external sphincter activity which precedes and outlasts the actual cough which is marked by the arrow. The response is greater in the patient with spinal transection through the third lumbar segment. 
the patient ceases to strain the external sphincter contracts once more. At the same time the perineum can be seen to return inwards to the normal resting position. This is part of the closing reflex which restores the pelvic floor to its state of active tonic contraction at rest.

Direct Stimulation of the Anal Canal. (a) Skin Stimulation. This represents the afferent component of the classical anal reflex; the motor response is a brisk volley of activity in time with the observed contraction of the anus (fig. 9). The time interval between stimulus and response is approximately one tenth of a second.

(b) Digital Stimulation of the Anal Canal. Digital examination of the anal canal stimulates increased external sphincter contraction which is followed by relaxation, but after a short interval the external sphincter once more assumes a steady resting contraction (fig. IO). A light pull on the sphincter or any movement along the anal canal excites a brisk contraction (fig. I0). Withdrawing the finger slowly from the anus initially excites an increased external sphincter contraction, which is followed by relaxation. As the finger finally leaves the anal canal a brisk contraction closes the anus. A brief interval of partial relaxation then preceeds the reappearances of normal resting contraction.

In paraplegic subjects at any level of cord transection above $\mathrm{L}_{3}$, stimulation of the anal canal is at first excitatory. However, movement of an object along the anal canal or prolonged stretching of the ano-rectal ring and sphincters leads quickly to relaxation. When the stimulus is withdrawn reflex contraction returns to the external sphincter. The time interval required for the return of tonic contraction varies, it may be immediate or as long as nine seconds. We found that the delay is related to the degree of stretching inflicted on the anal sphincters. The reappearances of resting contraction coincides with closure of the anal canal.

Digital traction on the ano-rectal ring reveals one other interesting point. As in the previous experiment the external sphincter is inhibited and the whole sphincter mass can be felt to give way after an initial contraction. Observation of the anus at this stage shows that it is widely open, proving conclusively that anal stretching inhibits the internal as well as the external sphincter.

(c) Distension of the Anal Canal by Inflating Balloon. In our experiments the anal canal was distended by means of a Miller-Abbot balloon placed within it (fig. I $a$ ). Measured volumes of air were injected into the balloon. Initially the effect on the external sphincter was excitatory, but with 50 to $100 \mathrm{ml}$. of air in the balloon this muscle relaxed (fig. II). On emptying the balloon the external sphincter slowly resumed its normal tonic contraction.

\section{REFLEX RESPONSES TO DISTENSION OF THE RECTUM}

So far we have dealt with the effects of stimuli applied to the anal canal. It is also of interest to explore the relationships between the external sphincter and the rectum. We have investigated this problem by distending the rectum with a balloon and recording changes in the external sphincter activity (fig. $\mathrm{I} b$ ). This type of experiment was carried out on 24 patients with complete spastic paraplegia, the level of cord transection varying from $\mathrm{C}_{5}$ down to $\mathrm{L}_{3}$. 


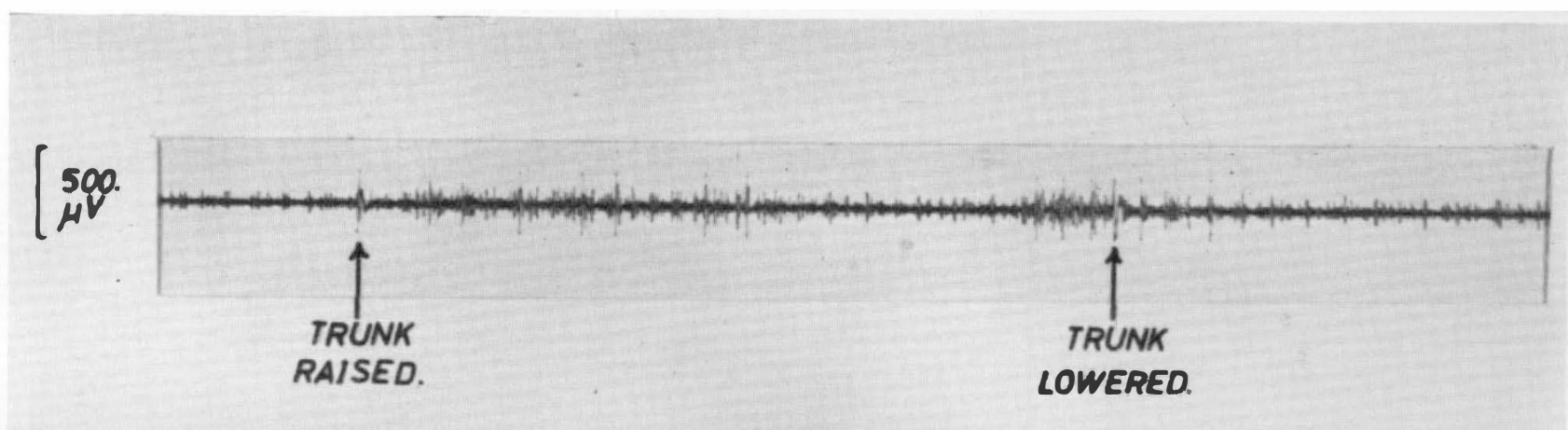

PARAPLEGIA LIL

FIG. 7

External sphincter activity is recorded while patient elevates his trunk by pulling upwards on a bar. At the first signal a burst of increased activity is seen as the trunk is raised: this settles down as the position is maintained. A further increase in activity occurs as the trunk is lowered; this ceases shortly after the position of rest is reached at the second signal.

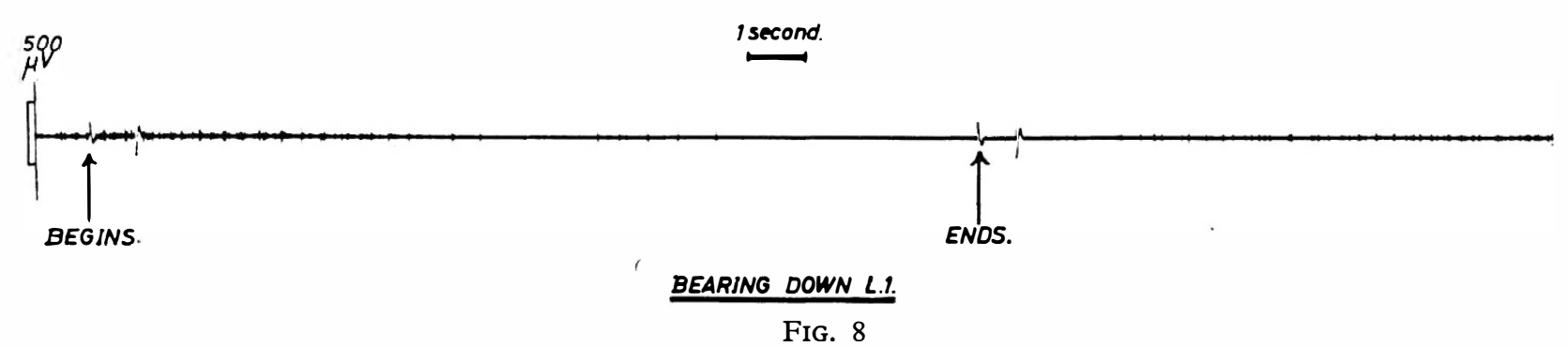

FIG. 8

Bearing down which commences at the first signal induces a transient increase in external sphincter contraction which is followed by complete relaxation. When bearing down ceases at the second signal, there is a short interval and then activity reappears in the external sphincter as it contracts. (Paraplegia LI.) 
Figure 12 shows the results of rectal distension in a case of paraplegia below T9. With each increase of intra-rectal volume the external sphincter responds by contracting. However, as the rectal wall relaxes to accommodate the increased volume the external sphincter relaxes as well and the level of resting activity falls below the previous level. As filling proceeds the excitatory effect diminishes and the relaxation of the external sphincter increases until it is complete. Examination of the anus at this stage shows that it is closed, so that the internal sphincter must still be active or else the anus would fall open. We have not found in any of these cases that the anus gapes on rectal filling.

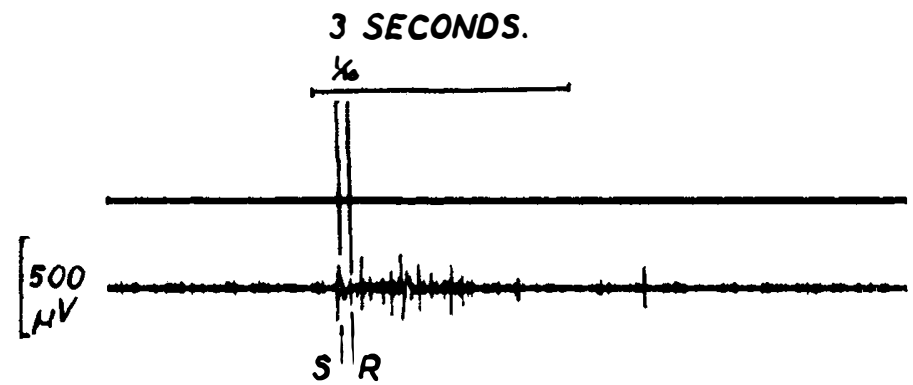

ANAL REFLEX L.3.

FIG. 9

The anal reflex is elicited by pricking the perianal skin. The interval between the stimulus ' $S$ ' and the response ' $R$ ' is approximately $I /$ IO second. (Paraplegia L3.)

A simultaneous record of intra-rectal pressure changes shows that initially filling is resisted and pressure rises to a peak, then relaxation of the rectal wall occurs and the pressure falls to a new resting level (fig. 13). With each increase in volume intra-rectal pressure rises in a series of steps, until the experiment terminates when the external sphincter is relaxed.

In I 5 of our patients this sequence of events was terminated within the space of one minute by automatic defaecation. In three patients with paraplegia above $\mathrm{T}_{5}$, defaecation did not occur and in six of them with lesions below TI I it was achieved by voluntary straining. In all our cases rectal distension caused complete relaxation of the external sphincter ani. These results are summarised in Tables II and III. Study of these tables shows that in those patients in whom automatic defaecation occurs the degree of rectal filling needed is fairly constant and in only two cases does it exceed $150 \mathrm{ml}$. On the other hand there is a greater variation in intra-rectal volume with a higher mean volume and lower mean pressure in those cases in whom defaecation did not occur or required some voluntary effort by the patient.

In those patients in whom rectal distension causes automatic defaecation the external sphincter remains inhibited until defaecation is complete, at the end of the act the electromyogram shows a sharp burst of activity (fig. I4). This coincides with closure of the anus and represents the closing reflex.

When automatic defaecation did not occur, relaxation of the external sphincter persisted until defaecation was either achieved by voluntary bearing down or the balloon was deflated and removed from the rectum. We were interested to know 
TABLE II

\begin{tabular}{|c|c|c|c|c|}
\hline $\begin{array}{l}\text { LESION } \\
\text { All complete } \\
\text { and spastic }\end{array}$ & $\begin{array}{c}\text { Relaxation } \\
\text { of external } \\
\text { sphincter }\end{array}$ & $\begin{array}{l}\text { Intra-rectal } \\
\text { volume } \\
\text { ml. }\end{array}$ & $\begin{array}{l}\text { Pressure } \\
\text { mm. Hg. }\end{array}$ & $\begin{array}{l}\text { Automatic } \\
\text { defaecation }\end{array}$ \\
\hline $\mathrm{C}_{5}$ & + & I 50 & 45 & + \\
\hline $\mathrm{T}_{5}$ & + & I 50 & 53 & + \\
\hline $\mathrm{T}_{5}$ & + & 100 & 43 & + \\
\hline $\mathrm{T}_{5}$ & + & IOO & 72 & + \\
\hline T6 & + & I 50 & 52 & + \\
\hline T6 & + & I 50 & 55 & + \\
\hline $\mathrm{T}_{7}$ & + & 100 & 55 & + \\
\hline $\mathrm{T}_{7}$ & + & IOO & 50 & + \\
\hline $\mathrm{T}_{7}$ & + & I 50 & 65 & + \\
\hline T8 & + & 100 & 50 & + \\
\hline $\mathrm{T}_{9}$ & + & 200 & 48 & + \\
\hline Tio & + & I 50 & 50 & + \\
\hline TI2 & + & 100 & 50 & + \\
\hline L3 & + & 250 & 52 & + \\
\hline L3 & + & 100 & 50 & + \\
\hline \multicolumn{5}{|c|}{ Mean volume $\mathrm{I} 40 \mathrm{ml}}$. \\
\hline
\end{tabular}

In 15 patients the external sphincter ani is relaxed by balloon distension of the rectum. In every case the experiment was terminated by automatic defaecation within the space of one minute. The mean volume required was $140 \mathrm{ml}$. and the mean pressure $53 \mathrm{~mm}$. $\mathrm{Hg}$.

TABLE III

\begin{tabular}{|c|c|c|c|c|}
\hline $\begin{array}{c}\text { LESION } \\
\text { All complete } \\
\text { and spastic }\end{array}$ & $\begin{array}{c}\text { Relaxation } \\
\text { of external } \\
\text { sphincter }\end{array}$ & $\begin{array}{l}\text { Intra-rectal } \\
\text { volume } \\
\text { ml. }\end{array}$ & $\begin{array}{l}\text { Pressure } \\
\mathrm{mm} . \mathrm{Hg} .\end{array}$ & Defaecation \\
\hline $\mathrm{T}_{7}$ & + & 150 & 42 & No \\
\hline $\mathrm{T} 8$ & + & 200 & 48 & No \\
\hline $\mathrm{T}_{9}$ & + & I 50 & 45 & No \\
\hline TII & + & 200 & 55 & $\begin{array}{l}\text { Voluntary } \\
\text { straining }\end{array}$ \\
\hline TII & + & I 50 & 50 & , \\
\hline TII & + & 150 & 55 & ” \\
\hline $\mathrm{L}_{\mathbf{I}}$ & + & 300 & 32 & ” \\
\hline $\mathrm{LI}_{\mathrm{I}}$ & + & 200 & 45 & , \\
\hline $\mathrm{L}_{3}$ & + & 250 & 50 & " \\
\hline \multicolumn{2}{|c|}{ Mean volume I $94 \mathrm{ml}}$. & \multicolumn{3}{|c|}{ Mean pressure $47 \mathrm{~mm}$. Hg. } \\
\hline
\end{tabular}

In nine patients the external sphincter ani is relaxed by balloon distension of the rectum. Automatic defaecation did not occur. In six patients with abdominal muscle function defaecation was achieved by straining. The volumes and pressures required to relax the external sphincter ani vary. 


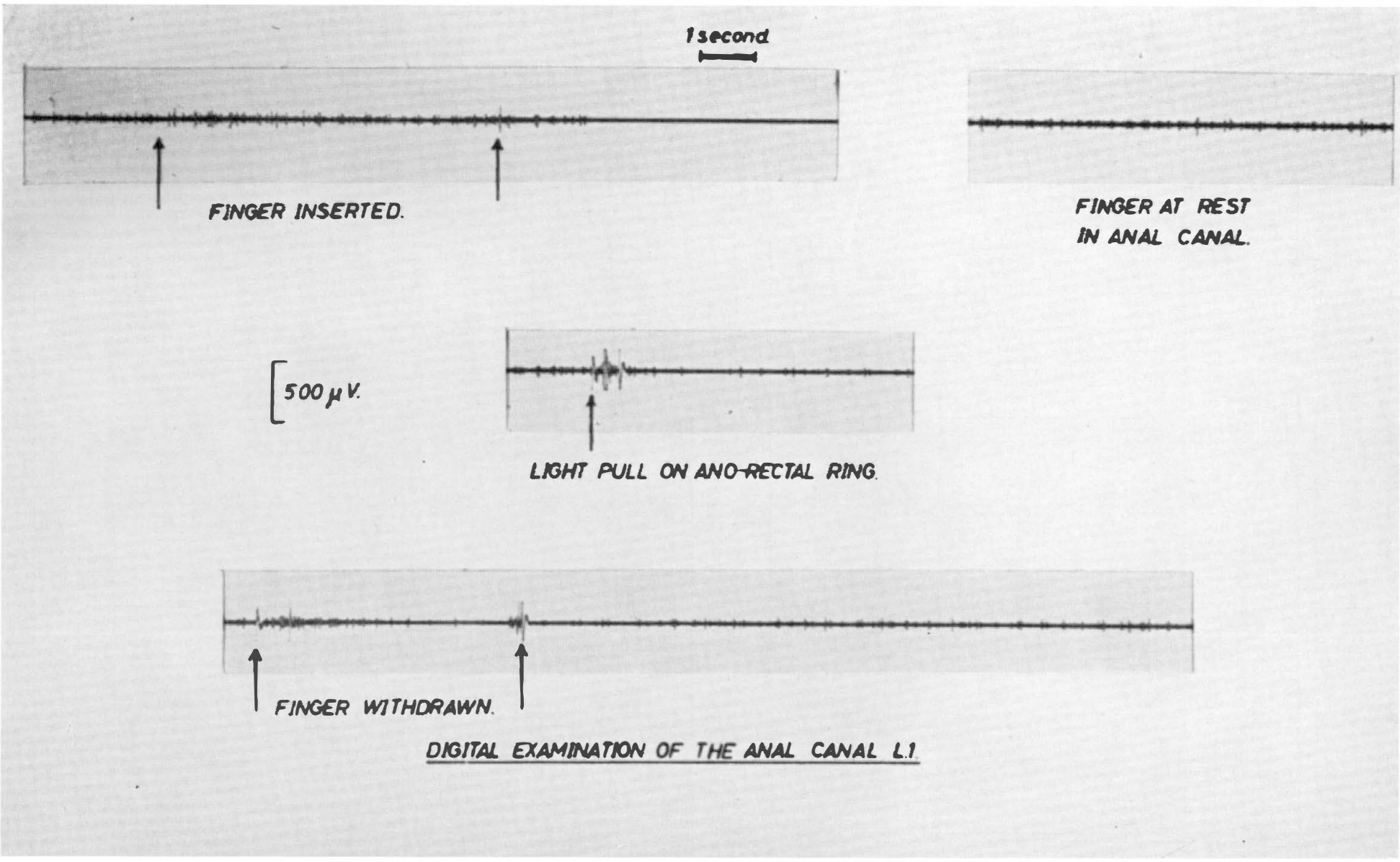

Fig. IO

Digital examination of the anal canal. In the left-hand upper tracings the index finger is inserted into the anal canal between the two signal marks. Initially the external sphincter contracts briefly but then relaxes. After a short interval during which the examining finger is held still, the external sphincter returns to a steady resting contraction which is maintained.

Light traction on the ano-rectal ring excites a brief contraction of the external sphincter. When the finger is withdrawn from the anal canal the external sphincter contracts at first and then relaxes. As the finger leaves the anal canal a short burst of activity is seen; this is succeeded by partial relaxation again before normal resting activity is re-established. (Paraplegia LI.) 

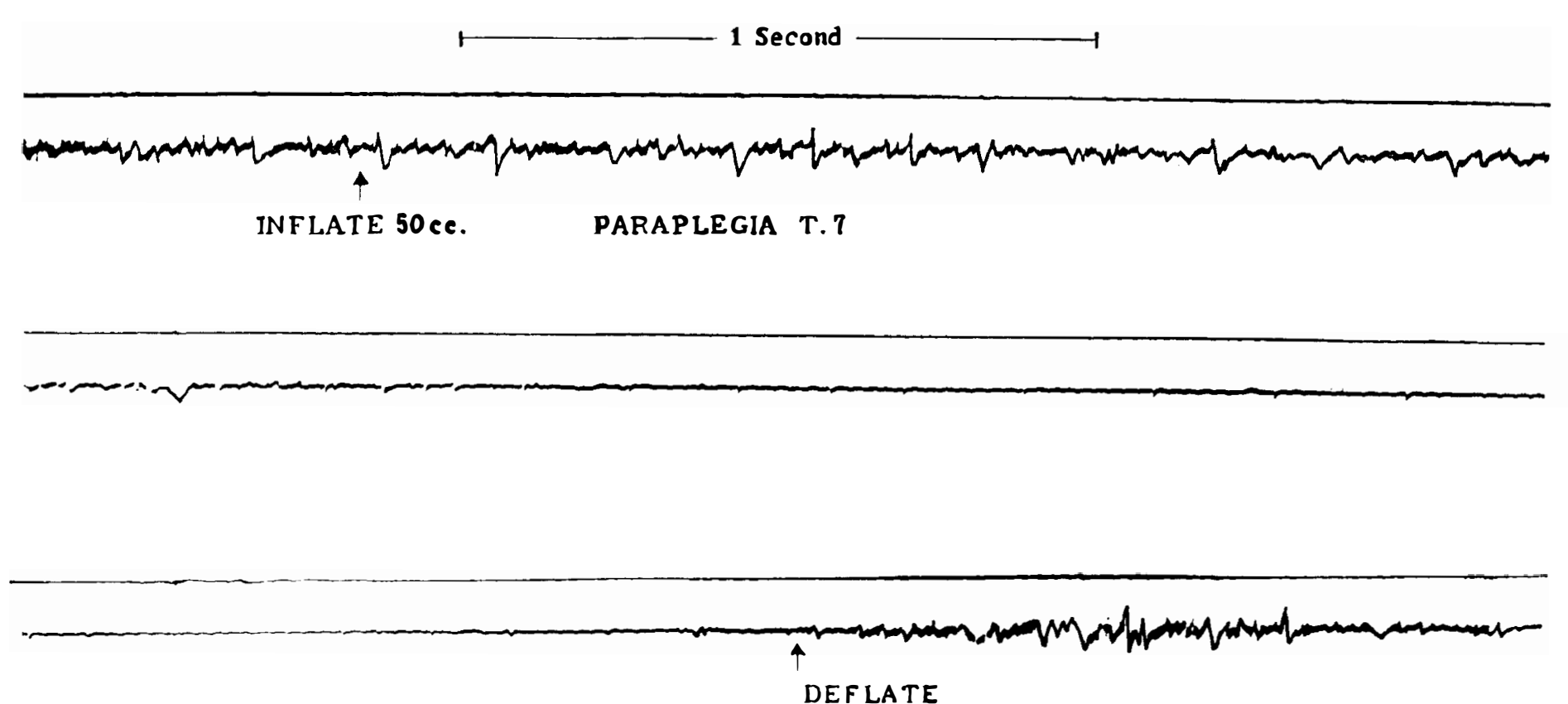

DEFLATE

\section{BALLOON INFLATION - ANAL CANAL}

FIG. II

Balloon distension of the anal canal. Resting activity is present with an empty balloon in the anal canal. Between the signal markers the balloon is inflated with $50 \mathrm{ml}$. of air: the external sphincter responds with an initial contraction and then relaxation. Relaxation persists while the balloon remains inflated. Resting contraction takes about 8 seconds to re-appear after the balloon is emptied. (Paraplegia T7.) 


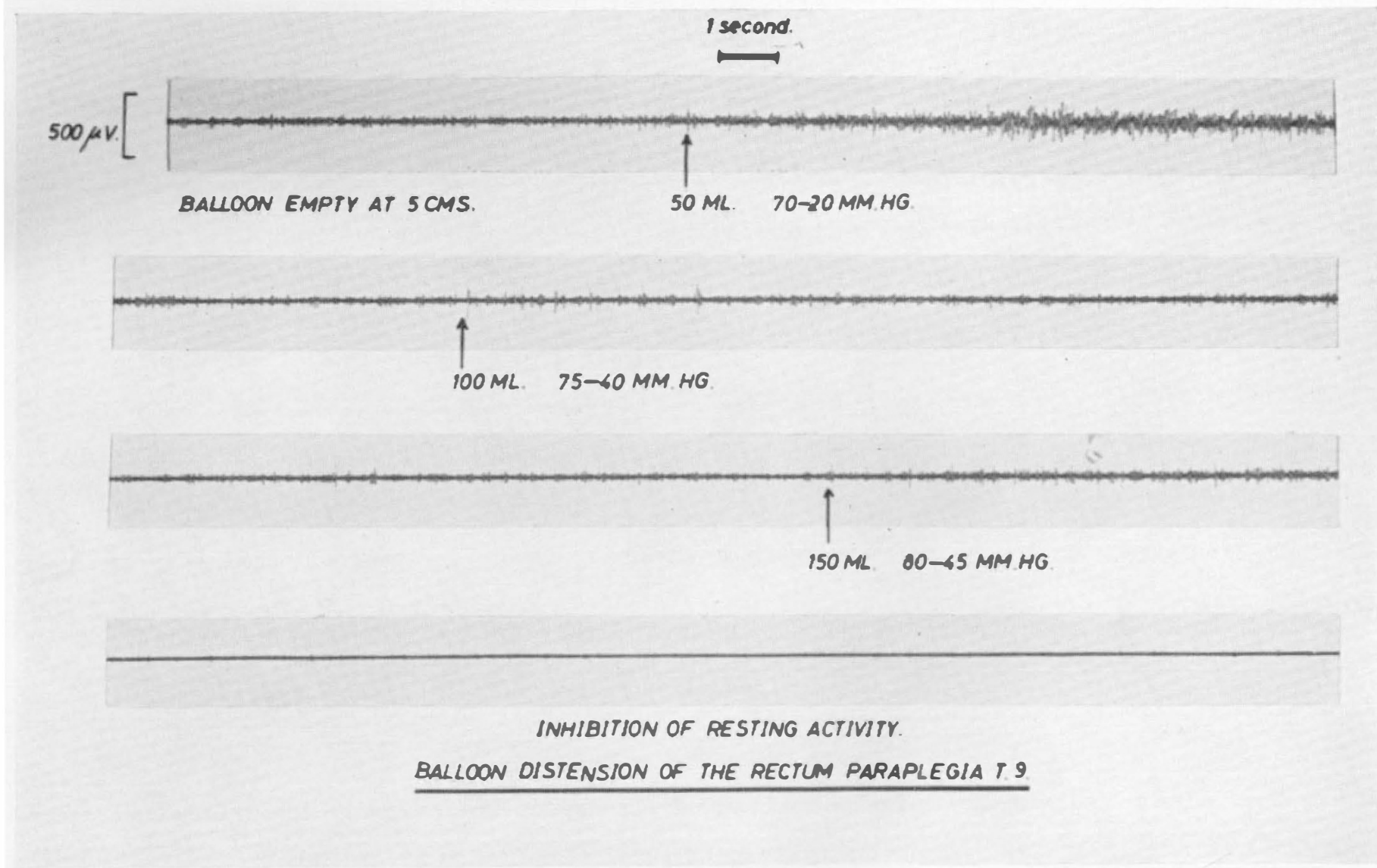

FIG. I2

Balloon distension of the rectum. Resting activity is present in the external sphincter ani with an empty balloon in the rectum $5 \mathrm{~cm}$. above the anal verge. At each arrow $50 \mathrm{ml}$. of air is injected into the balloon. This produces an increase in activity each time, which is succeeded by an increasing degree of relaxation of the external sphincter. Relaxation of the external sphincter is complete one minute after $150 \mathrm{ml}$. of air has been injected. The anus remains shut. (Paraplegia T9.) 


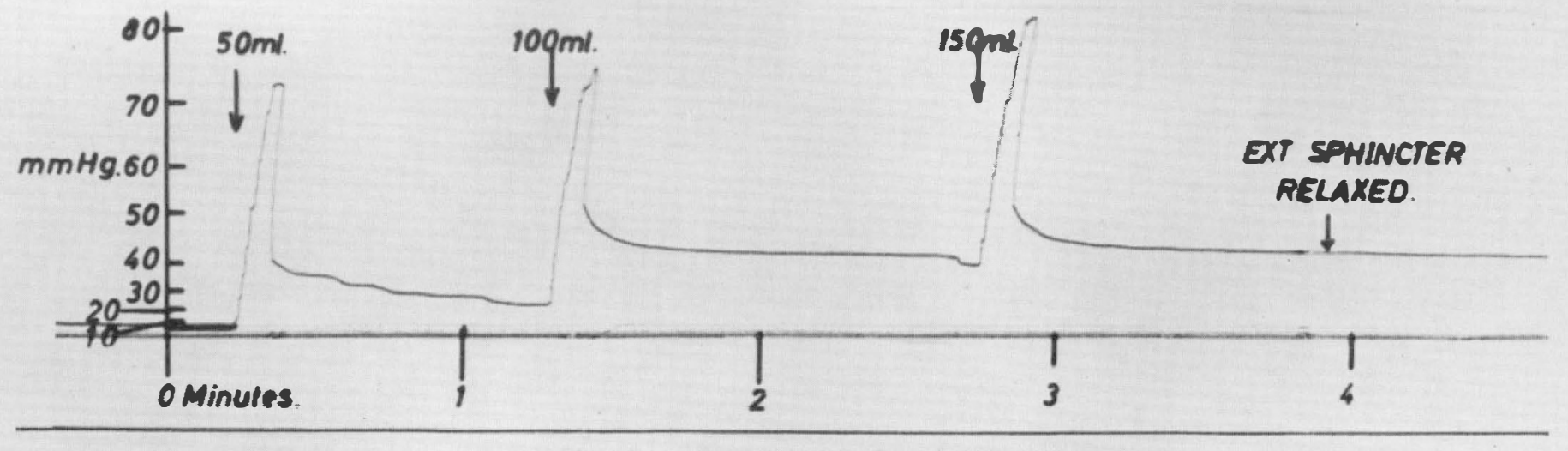

RECTAL PRESSLRE TRACING T.9.

FIG. I3

Pressure changes within the rectal balloon during the experiment illustrated in Figure 12. At each arrow $50 \mathrm{ml}$. of air is injected into the balloon. Initially the rectal wall resists distension and a peak is obtained; as the rectal wall relaxes the pressure falls to a new resting level over the course of a minute. Time in minutes is plotted against pressure in millimetres of mercury. 

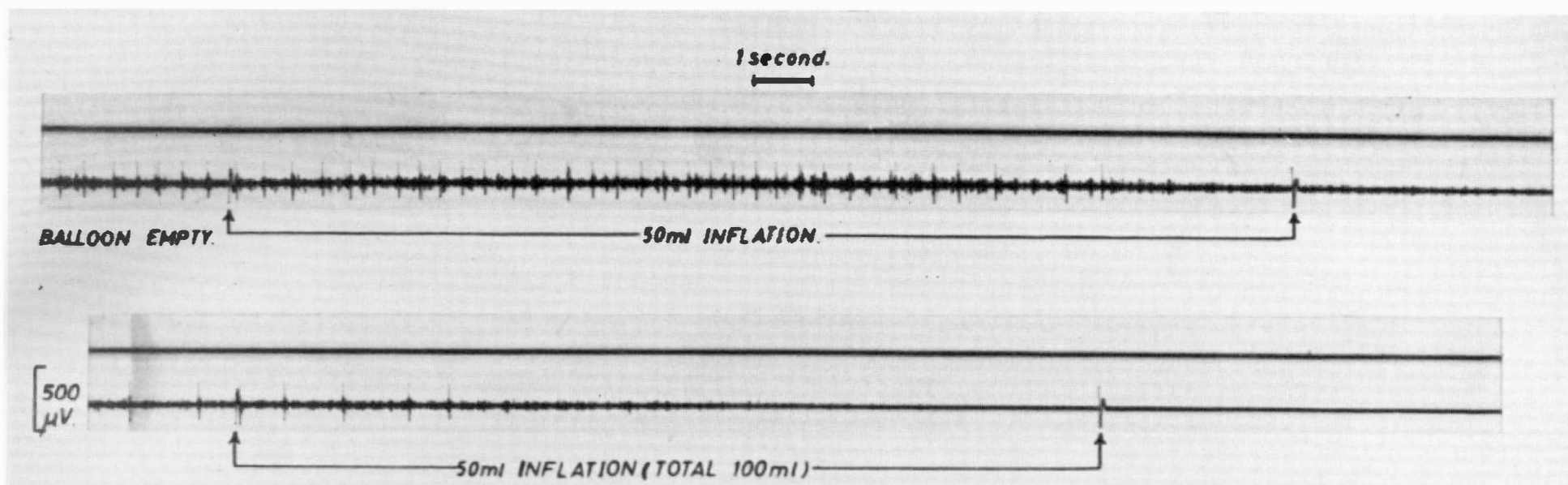

SOmI INFLATION(TOTAL $100 \mathrm{ml})$
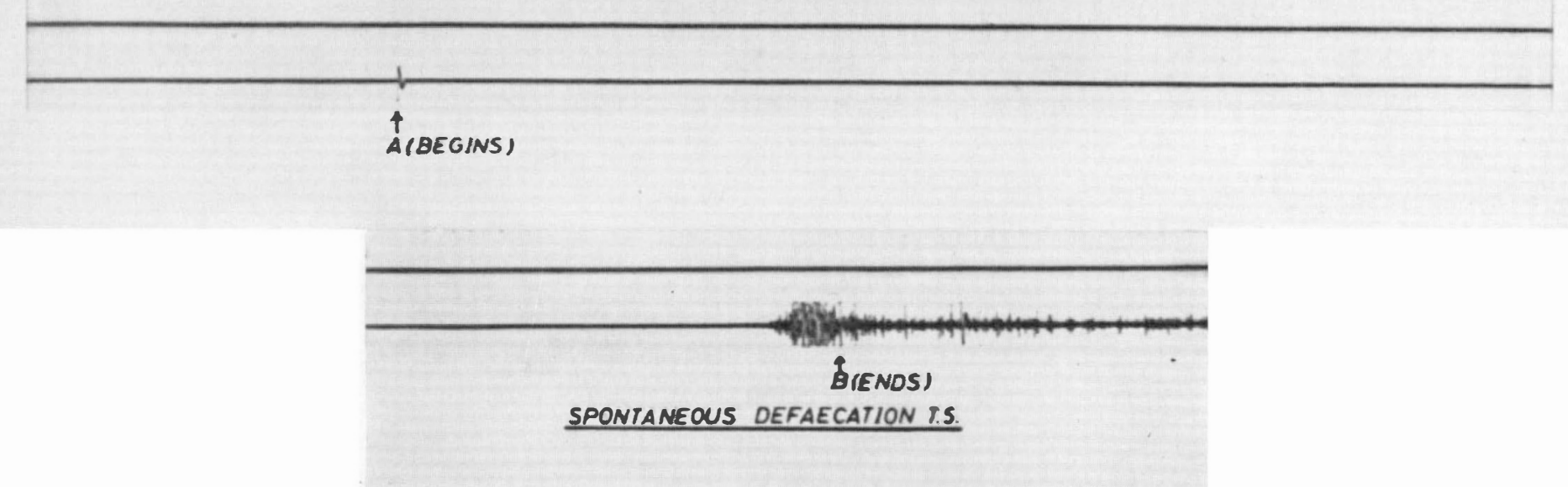

\section{FIG. I4}

An intra-rectal balloon is successively inflated with $50 \mathrm{ml}$. of air to a total of $100 \mathrm{ml}$. Inflation occurs between the signals on the electromyogram. The first $50 \mathrm{ml}$. causes external sphincter contraction initially and then partial relaxation. The second 50 ml. causes relaxation before injection is complete. Subsequently a spontaneous rectal contraction occurs and is followed by defaecation; during this the sphincter remains relaxed. A brisk closing reflex appears at the end of defaecation; the anus closes and resting activity returns to the sphincter. (Paraplegia T5.) 
how effective the inhibitory effects of rectal distention were in the presence of stimuli. In further experiments to investigate this problem we induced complete relaxation of the external sphincter by inflating a balloon in the rectum and then applying stimuli to it such as pricking peri-anal skin and coughing. It was found that once the external sphincter is inhibited by rectal distension its responses to excitatory stimuli are depressed and transient, and the muscle subsequently remains in the relaxed state until the rectum is emptied.

This type of experiment may be taken a stage further and the anal canal repeatedly stimulated to see what happens when the rectum is filled. Further experiments were carried out in which an intra-rectal balloon was filled with $50 \mathrm{ml}$. of air, an amount insufficient to inhibit the external sphincter. The anal canal was then stimulated by digital examination. In Figure 15 the results of such an experiment in a patient with complete spastic paraplegia below $\mathrm{T}_{5}$ are shown. The effects of continuing digital stimulation of the anal canal in the presence of partial rectal filling are striking. Not only is the external sphincter rapidly inhibited but the rectal wall is excited to contract so that automatic defaecation occurs.

\section{DISCUSSION}

The outstanding feature of our results is the finding that the external sphincter shows continuous electrical activity and tonic contraction at rest following transection of the cord above the level of the third lumbar segment. This activity is, however, absent during the stage of spinal shock in these cases. It is also abolished in transection above $\mathrm{L}_{3}$, following intrathecal alcohol block, and in traumatic lesions affecting the sacral segments and their peripheral outflow. Furthermore, the absence of continuous activity in the external sphincter at rest was also found in tabes dorsalis, which proves the importance of the proprioceptive pathways in maintaining postural tone of the external sphincter. These observations signify the importance of the sacral segments and their efferent as well as afferent pathways in maintaining external sphincter tone and confirm Starling's (1900) and Matti's (1909, I910) findings in man and Masius's (1868) and Bishop's et al. (1956) experiments in animals. Denny-Brown and Robertson (1935), investigating the nervous control of defaecation, came to the conclusion that the postural tone of the sphincter ani is 'essentially unaffected by transverse lesions and changes in tonicity reflect only the degree of activity of the rectum and possibly the distal colon'. They further stated that 'the external sphincter ani is not tonic although it contracts reflexly and synergistically'. The evidence provided by the present investigations is not in accordance with these views. That changes in tonicity of the external sphincter do not reflect only the degree of activity of the rectum has been proved by our findings on reflex responses of this muscle to raised intra-abdominal pressure. These responses still take place after excision of the rectum, including the internal sphincter and anal mucosa (Porter, 1962) and Parks, Porter and Melzak (1963).

The external sphincter was found to be very sensitive to changes in intraabdominal pressure. Increase of intra-abdominal pressure exerts a dual effect. In most instances, it reinforces the tonic contraction already present in the pelvic muscles and external sphincter, thus securing closure of the anal canal against the expulsive forces acting on them. This initial excitation of the external sphincter tone is, however, abolished if the intra-abdominal pressure is maintained or increased by bearing down and relaxation of the external sphincter follows. Taverner and Smiddy (1959) believed that pelvic muscular relaxation requires cerebral 


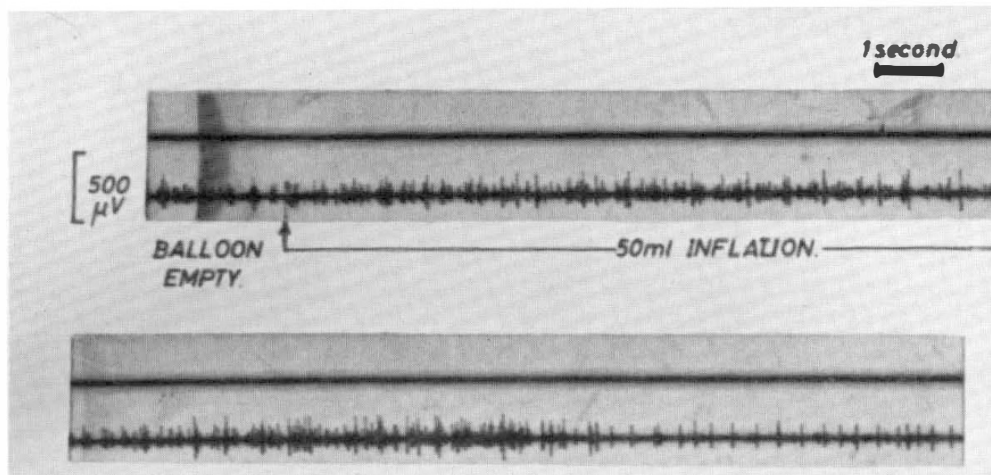

FINGER INSERTED INTO ANAL CANAL

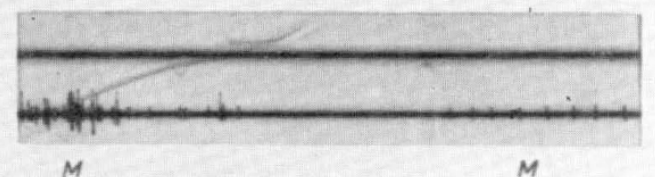

M

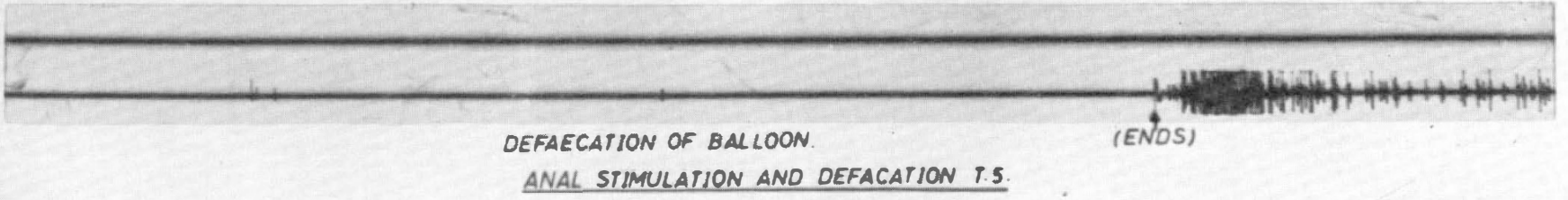

FIG. I5

An intra-rectal balloon is inflated with $50 \mathrm{ml}$. of air (upper tracing). After an interval the external sphincter is still contracting Insertion of a finger into the anal canal produces sphincter contraction. In the following records the examining finger is moved up and down the anal canal at the points marked ' $M$ '. The first of these is followed by relaxation, which is barely interrupted by subsequent finger movement. A moderate sphincter contraction accompanies withdrawal of the finger, which is then followed by a period of complete relaxation during automatic defaecation of the rectal balloon. Reflex activity returns as the balloon is leaving the anal canal. (Paraplegia T5.) 
inhibitory impulses. While these play an important part in normal subjects, our findings in complete transection of the cord indicate that afferent impulses arising from increased intra-abdominal pressure by bearing down initiate a complex reflex action of the isolated cord by exerting excitatory effects-i.e. contraction of the terminal colon and rectum on the one hand and inhibitory effects on the internal and external sphincters on the other, resulting in their relaxation and automatic evacuation.

In our experiments, rectal distension not infrequently excited rectal contraction in response to which the distending mass moved caudally into the anal canal. We have found that distension of the anal canal inhibits the tonic contraction of the external sphincter. The resulting relaxation of this and the other pelvic muscles is maintained to allow unresisted evacuation of the rectum once it has started. With the closure of the anal canal following evacuation of the rectum coincides the reappearance of the resting contraction of the external sphincter (closing reflex).

The volume of rectal contents required to initiate automatic evacuation was found to be fairly constant and varied little in paraplegic patients. However, if automatic evacuation is not well established, difficulty in emptying the rectum may arise and the intrarectal volume needed to inhibit the external sphincter tone and produce its relaxation tends to be greater. As a result, the rectum becomes stretched and distended and the threshold needed to initiate reflex evacuation is correspondingly raised. This is a point of considerable practical importance in the management of the bowel function in paraplegic patients. Amongst the measures practised at the Stoke Mandeville Centre to establish regular and satisfactory automatic evacuation are certain laxatives, which elicit increased activity of the terminal colon, secondly increase of intra-abdominal pressure, either by straining, manually or reflexly, and last but by no means least digital stimulation of the anal canal. In this connection, our studies on distension of the anal canal, in particular the relaxation of the whole sphincter mass following digital traction on the ano-rectal ring, appear to be of special interest.

\section{SUMMARY}

Electromyographic studies on the reflex activity of the external anal sphincter were carried out in 42 patients with lesions of the spinal cord. All cases, with the exception of one (tabes dorsalis), were complete lesions at various levels of the cord.

The external anal sphincter was found to show continuous tonic contraction at rest which depends on the integrity of the sacral segments and their peripheral outflow.

Factors eliciting reflex excitation and inhibition resulting in increased contraction or relaxation of the tone of the external anal sphincter are described in detail. In particular the effects of increased intra-abdominal pressure, skin stimulation and distension of the anal canal and rectum are reported.

The reflex mechanism of defaecation is discussed in the light of the management of bowel function in paraplegia.

Acknowledgments. We are grateful to Dr. L. Guttmann for the provision of research facilities in the National Spinal Injuries Centre. We are also greatly indebted to him for advice, criticism and encouragement in the preparation of this paper.

We also wish to record our thanks to Professor H. J. B. Atkins for research 
facilities in the Surgical Professorial Unit at Guy's Hospital. For similar reasons we are grateful to Dr. B. C. Morson, Dean of Post-Graduate Studies at St. Mark's Hospital.

\section{RÉSUMÉ}

L'activité réflexe du sphincter anal externe a été étudié grâce à l'éléctromyographie dans 42 cas de lésions de la moëlle épinière. Tous les cas étudiés, à l'exception d'un cas de tabès, ont presentés une lésion complète de la moëlle épinière à diffèrents niveaux.

Le sphincter anal externe, à l'état de repos, est la siège d'une activité tonique continuelle qui depend de l'intègrité des ségments sacrés et des nerfs péripheriques qui en dependent.

Les facteurs d'excitation et d'inhibition sur le tonus du sphincter anal externes sont décrits, en détail, dans le texte; en particulier les effets de l'augmentation de la pression intra-abdominale, la stimulation cutanée, ainsi que la distension de l'anus et du rectum.

Le méchanisme du reflexe défacatoire est discuté en relation du traitement de cette fonction dans la paraplégie.

\section{ZUSAMMENFASSUNG}

Bei 42 Patienten mit Rückenmarksverletzungen wurde die Reflexaktivität des Sphincter ani externus elektromyographisch untersucht. Mit einer Ausnahme (Tabes dorsalis) handelte es sich in allen Fällen um komplette Lähmungen verschiedener Höhe.

Der Sphincter ani externus zeigte in der Ruhe dauernde tonische Kontraktion. Dies beruht auf der normalen Funktion der Sakralsegmente und ihrer peripheren Nervenversorgung.

Die verantwortlichen Faktoren für Reflexerregung und Hemmung, welche erhöhte Kontraktion oder Entspannung des Sphinkter ani externus bedingen, werden im Einzelnen beschrieben. Insbesonders werden die Folgen erhöhten intraabdominalen Drucks, verschiedener Hautreize und der Distension des Anal-Kanals und des Rektum beschrieben. Die Reflexfunktion der Defäkation wird erörtet mit besonderer Berücksichtigung der Wiederherstellung der Darmfunktion beim Paraplegiker.

\section{REFERENCES}

Adrian, E. D., \& Bronk, D. W. (I928). F. Physiol. (Lond.), 66, 8I.

Beck, A. (1930). Pflïger's Arch. ges. Physiol. 224, 278.

Bishop, B., GARry, R. C., RoberTs, T. D. M., \& TODD, J. K. (I956). F. Physiol. (Lond.), 134, 229.

Bors, E., \& Blinn, K. A. (I958). Proc. 7th Ann. Clin. Paraplegia.

DenNY-Brown, D., \& Robertson, E. G. (1935). Brain, 58, 256.

FloYd, W. F., \& Walls, E. W. (I935). F. Physiol. (Lond.), 49, I2I.

Frankl-Hochwart, L. V., \& Fröhlich, A. (I900). Pflüger's Arch. ges. Physiol. 81, 420.

Gaston, E. A. (1948). Surg. Gynec. Obstet. 87, 280.

Goligher, J. C., \& Hughes, E. S. R. (I95I). Lancet, I, 543.

Gowers, W. R. (I877). Proc. roy. Soc. Lond. 26, 77.

Guttmann, L. (1947). Proc. R. Soc. Med. 40, 219.

Guttmann, L. (I953). Monograph in Vol. Surgery, Medical History of the Second World War, p. 422. London: Her Majesty's Stationery Office.

Hall, M. (1836). Lectures on the Nervous System. London.

HEAD, H., \& RIDDOCH, G. (I9I7). Brain, 40, I88.

HURST, A. F. (I909). Constipation and Allied Intestinal Disorders. London.

LANGWorthy, O. R., \& Rosenberg, S. J. (I939). F. Neurophysiol. (Lond.), 2, 356.

Liddel, E. G. T., \& Sherrington, C. S. (I924). Proc. roy. Soc. B, 96, 2 I2.

Masius, P. (1868). Bull. Acad. roy. Méd. Belg. I, 491.

Matti, H. (I909). Dtsch. Z. Chir. IoI, 70.

Muller, J. (I834). Handbuch d. Physiol.

Parks, A. G., Porter, N. H., \& Melzak, J. Dis. Colon Rect. Dec. 1963.

Petersen, I., \& Franksson, C. (I955). Brit. F.Urol. 27, I48.

Porter, N. H. (1961). Proc. R. Soc. Med. 54, I043.

Porter, N. H. (I962). Ann. R. Coll. Surg. Engl. 31, 379.

SHERRINGTON, C. S. (1915). Brain, 38, I9I.

Starling, E. H. (I900). Shafer's Textbook of Physiology. Edinburgh.

Taverner, D., \& Smiddy, F. G. (I959). Dis. Colon Rect. 2 , I 53. 